\title{
EDITORIAL
}

\section{Neutrophils, airway hyperresponsiveness and COPD: true, true and related?}

\author{
Charles G. Irvin
}

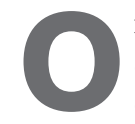
nce upon a time distinguishing between COPD and asthma in a smoking or ex-smoking patient was easy: a patient who smoked, had a low diffusing capacity of the lung for carbon monoxide or a hyperlucent radiogram, and no bronchodilator response was labelled as COPD; whereas a patient who, whether they smoked or not, had a bronchodilator response and airway hyperresponsiveness (AHR) was an asthmatic. Nothing could be simpler; that is until studies of asthmatics included measurements of inflammation and studies of patients with COPD included performing methacholine challenges. We now know that significant bronchodilator responses can be present in many patients with COPD [1] and, as discussed below, airway responsiveness is also not a stable feature of asthma. As determined by unbiased analysis, such as cluster or factor analysis, asthma [2,3] and COPD [4] both have been shown to have distinctly different clinical phenotypes. While there is no doubt that these phenotype assignments will prove to be variable, irreproducible and effervescent, at least this clustering of patients' characteristics provides a conceptual framework to advance the field. The clinical significance is that if a patient with airway disease is assigned a phenotype, then a targeted, effective treatment will be forthcoming, or at least that is the hope.

AHR was long touted as a "hallmark" of asthma but we now know that hyperresponsiveness is a characteristic of many inflammatory lung diseases [5, 6]. In asthma, hyperresponsiveness is a well-studied end-point relating, in some patients, to inflammation [6], but this is not always the case, as we observed in patients on inhaled corticosteroids (ICS) [7] and obese asthmatics [8]. Moreover, like bronchodilator responses in patients with COPD, AHR in asthmatics is not always temporally stable $[7,9]$, but it is recognised that AHR is related to disease severity and progression. Yet, in spite of over 50 years of intense investigation, the mechanism(s) of AHR in patients remains poorly understood [10]. Regardless of the disease in question, hyperresponsiveness is an undesirable feature that, if given the right therapeutic intervention, should return to normal.

In this issue of the European Respiratory Journal (ERJ), VAN DEN BERGE et al. [11] report a secondary analysis from the previously

Vermont Lung Center, University of Vermont, Burlington, VT, USA.

CORRESPONDENCE: C.G. Irvin, Vermont Lung Center, University of Vermont, Room 226, HSRF, 149 Beaumont Avenue, Burlington, VT 05405-0075, USA. E-mail: charles.irvin@uvm.edu published GLUCOLD (Groningen Leiden Universities Corticosteroids in Obstructive Lung Disease) study [12]. A group of 114 subjects were randomised to four 30-month study arms: placebo, fluticasone/salmeterol (500/50 $\mu \mathrm{g}$ b.i.d.), fluticasone $(500 \mu \mathrm{g})$, and 6 months of fluticasone $(500 \mu \mathrm{g})$ followed by 24 months of placebo. The patients were Global Initiative for Chronic Obstructive Lung Disease stage II or III and smokers or former smokers. Baseline, and 6- and 30-month measurements were performed: AHR (provocative concentration of methacholine causing a $20 \%$ fall in forced expiratory volume in $1 \mathrm{~s}$ (FEV1)) was determined, sputum inducted and bronchial biopsies were taken. This is a truly remarkable study given the technical difficulty and the results that lead to important conclusions and ramifications both for further research and development of new approaches to treatment.

Methacholine challenge showed that AHR is common (94\%) in the GLUCOLD patients with COPD and was associated with female sex, eosinophilia, airway closure (residual volume (RV)/ total lung capacity (TLC) ratio), bronchodilator responses and decreased lung function. FEV1 and FEV1/forced vital capacity ratio, while related to inflammation, showed an association not just with neutrophils but other inflammatory cell types: macrophage, lymphocytes and eosinophils. A multivariate analysis revealed that neutrophils and lymphocytes are independent determinants of AHR. Following treatment, improved AHR was associated with a decrease in RV/TLC and inflammation, specifically in numbers of macrophages and neutrophils. The authors conclude that airways responsiveness defines an independent type or distinct phenotype of COPD; moreover, they conclude that AHR is a measure of underlying inflammation and, in particular, the presence of neutrophils. Of note is the finding that inflammation assessed with sputum induction was informative whereas biopsy-determined inflammation was not. Lastly, in these COPD patients, AHR is related to loss of postbronchodilator lung function that defines both COPD and its deadly progression.

Although the authors suggest there is a strong association of AHR and eosinophils in asthmatic patients, patients can exhibit AHR without inflammation or inflammation without AHR [13, 14], suggesting that the relationship between inflammatory cells and AHR is far from either direct or clear. How robust is the relationship between inflammation and AHR remains to be seen, especially as the inflammatory process of COPD is likely to be quite different than that in asthma and, as such, the free extrapolation of the experience in asthma to COPD may not be warranted. The relationship 
between neutrophilia and COPD is well recognised, but the association of neutrophils and AHR is not. In the 1980s, it was demonstrated that granulocytes (both neutrophils and eosinophils) cause AHR in an allergic animal model [15] and that a selective chemotactic agent for neutrophils, the complement fragment $\mathrm{C} 5 \mathrm{a}$ des-Arg, caused both lung remodelling and AHR [16]. At the time there was criticism of these studies because of the suggestion that neutrophils could ever be important to the pathogenesis of AHR in asthma. Yet neutrophils certainly have armamentarium capable of causing AHR and, in particular, we demonstrated that neutrophil cathepsin $\mathrm{G}$ and other inflammatory cell cationic proteins [17], like eosinophil cationic proteins, cause marked increases in AHR. We also suggested that AHR could be the consequence of the redundancies involving distinct or common mechanisms between inflammatory cells and not just the feature of a single type of inflammatory cell or mediator. Taken together and recast in terms of therapeutic targeting of inflammation, the results of the current study suggest that targeting common pathogenic pathways, such as blocking the downstream inflammatory cascade induced by the transcription factor nuclear factor- $\mathrm{\kappa} B$ and not a cell type or specific mediator, will eventually prove to be the most clinically effective strategy. In this regard, the power of combination therapies as used in the GLUCOLD study has both solid theoretical and proven therapeutic merit.

The association of AHR in these patients with COPD to elevated RV / TLC or, more specifically, airway closure deserves comment. There is compelling evidence in asthma and experimental asthma that inflammation is associated with airway closure and an enhanced propensity for airway closure, which in turn is a cause of AHR [18]. Other mechanisms that, in experimental animals, cause AHR, such as epithelial barrier disruption and smooth muscle hyperplasia, can and probably do play a role [19]. The evidence presented in the study by VAN DEN BERGE et al. [11] suggests enhanced airway closure is key. While there is a plausible relationship between eosinophils, interleukin-13/4, enhanced mucous secretion and enhanced airway closure in causing AHR in the allergic, nonobese asthmatic, it seems just as likely that the cause of neutrophilic inflammation and associated AHR in COPD could involve a similar sort of mechanism.

What are the clinical implications of this seminal study of VAN DEN BERGE et al. [11] in the current issue of the ERJ? The consistent finding both in asthmatics and now in patients with COPD that the combination of an inhaled steroid with a long-acting $\beta$-agonist (LABA) is efficacious is once again demonstrated. This is particularly important since, first, common wisdom holds that neutrophilia in COPD is steroid insensitive, and secondly, there may be something special about combining an ICS with a LABA. The combination of an ICS and a LABA probably activates a synergistic antiinflammatory mechanism [20], but a beneficial effect of ICS on $\beta_{2}$-adrenoceptor is also possible [21]. What is clear from this current study is the potential important measurement of airway responsiveness in patients with COPD that may prove to be insightful in terms of understanding the pathogenic mechanisms, guiding ongoing treatment schemes or selecting initial treatment schemes to halt the progression and mortality of COPD.

\section{SUPPORT STATEMENT}

This editorial was supported by the National Institute of General Medical Sciences of the National Institutes of Health (grant P30 GM103532), the National Heart Lung and Blood Institute (grants T32 HL076122 and R01 HL085464) and an American Lung Association Asthma Clinical Research Center Award to C.G. Irvin.

\section{STATEMENT OF INTEREST}

None declared.

\section{REFERENCES}

1 Calverley PM, Burge PS, Spencer S, et al. Bronchodilator reversibility testing in chronic obstructive pulmonary disease. Thorax 2003; 58: 659-664.

2 Moore WC, Meyers DA, Wenzel SE, et al. Identification of asthma phenotypes using cluster analysis in the Severe Asthma Research Program. Am J Respir Crit Care Med 2010; 181: 315-323.

3 Wenzel SE. Asthma phenotypes: the evolution from clinical to molecular approaches. Nat Med 2012; 18: 716-725.

4 Han MK, Agusti A, Calverley PM, et al. Chronic obstructive pulmonary disease phenotypes: the future of COPD. Am J Respir Crit Care Med 2010; 182: 598-604.

5 Crapo RO, Casaburi R, Coates AL, et al. Guidelines for methacholine and exercise challenge testing - 1999. This official statement of the American Thoracic Society was adopted by the ATS Board of Directors, July 1999. Am J Respir Crit Care Med 2000; 161: 309-329.

6 Tepper RS, Wise RS, Covar R, et al. Asthma outcomes: pulmonary physiology. J Allergy Clin Immunol 2012; 129: Suppl. 3, S65-S87.

7 Sumino K, Sugar EA, Irvin CG, et al. Methacholine challenge test: diagnostic characteristics in asthmatic patients receiving controller medications. J Allergy Clin Immunol 2012; 130: 69-75.

8 Dixon AE, Pratley RE, Forgione PM, et al. Effects of obesity and bariatric surgery on airway hyperresponsiveness, asthma control, and inflammation. J Allergy Clin Immunol 2011; 128: 508-515.

9 Cockcroft DW. Direct challenge tests: airway hyperresponsiveness in asthma: its measurement and clinical significance. Chest 2010; 138: Suppl. 2, 18S-24S.

10 O'Byrne PM. Conclusion: airway hyperresponsiveness in asthma: its measurement and clinical significance. Chest 2010; 138: Suppl. 2, $44 \mathrm{~S}-45 \mathrm{~S}$

11 van den Berge $\mathrm{M}$, Vonk JM, Gosman $\mathrm{M}$, et al. Clinical and inflammatory determinants of bronchial hyperresponsiveness in COPD. Eur Respir J 2012; 40: 1098-1105.

12 Lapperre TS, Snoeck-Stroband JB, Gosman MM, et al. Effect of fluticasone with and without salmeterol on pulmonary outcomes in chronic obstructive pulmonary disease: a randomized trial. Ann Intern Med 2009; 151: 517-527.

13 Crimi E, Spanevello A, Neri M, et al. Dissociation between airway inflammation and airway hyperresponsiveness in allergic asthma. Am J Respir Crit Care Med 1998; 157: 4-9.

14 Crimi E, Milanese M, Oddera S, et al. Inflammatory and mechanical factors of allergen-induced bronchoconstriction in mild asthma and rhinitis. J Appl Physiol 2001; 91: 1029-1034.

15 Murphy KR, Wilson MC, Irvin CG, et al. The requirement for polymorphonuclear leukocytes in the late asthmatic response and heightened airways reactivity in an animal model. Am Rev Respir Dis 1986; 134: 62-68.

16 Irvin CG, Berend N, Henson PM. Airways hyperreactivity and inflammation produced by aerosolization of human C5A des arg. Am Rev Respir Dis 1986; 134: 777-783. 
17 Coyle AJ, Ackerman SJ, Irvin CG. Cationic proteins induce airway hyperresponsiveness dependent on charge interactions. Am Rev Respir Dis 1993; 147: 896-900.

18 Irvin CG, Bates JH. Physiologic dysfunction of the asthmatic lung: what's going on down there, anyway? Proc Am Thorac Soc 2009; 6: 306-311.

19 Wagers S, Lundblad LK, Ekman M, et al. The allergic mouse model of asthma: normal smooth muscle in an abnormal lung? J Appl Physiol 2004; 96: 2019-2027.
20 Riesenfeld EP, Sullivan MJ, Thompson-Figueroa JA, et al. Inhaled salmeterol and/or fluticasone alters structure/function in a murine model of allergic airways disease. Respir Res 2010; 11: 22

21 Adner M, Larsson B, Säfholm J, et al. Budesonide prevents cytokine-induced decrease of the relaxant responses to formoterol and terbutaline, but not to salmeterol, in mouse trachea. J Pharmacol Exp Ther 2010; 333: 273-280. 